\title{
Atypical Mesonephric Hyperplasia of the Uterus Harbors Pathogenic Mutation of Kirsten Rat Sarcoma 2 Viral Oncogene Homolog (KRAS) and Gain of Chromosome 1q
}

\author{
HYUNJIN KIM ${ }^{1}$, NARA YOON ${ }^{2}$, HA YOUNG WOO ${ }^{3}$, EUI-JIN LEE ${ }^{4}$, \\ SUNG-IM DO $^{5}$, KIYONG NA ${ }^{6}$ and HYUN-SOO KIM ${ }^{1}$ \\ ${ }^{1}$ Department of Pathology and Translational Genomics, Samsung Medical Center, \\ Sungkyunkwan University School of Medicine, Seoul, Republic of Korea; \\ ${ }^{2}$ Department of Pathology, Incheon St. Mary's Hospital, College of Medicine, \\ The Catholic University of Korea, Incheon, Republic of Korea; \\ ${ }^{3}$ Department of Pathology, Severance Hospital, Yonsei University College of Medicine, Seoul, Republic of Korea; \\ ${ }^{4}$ Institute of Catholic Integrative Medicine, Incheon St. Mary's Hospital, College of Medicine, \\ The Catholic University of Korea, Incheon, Republic of Korea; \\ ${ }^{5}$ Department of Pathology, Kangbuk Samsung Hospital, \\ Sungkyunkwan University School of Medicine, Seoul, Republic of Korea; \\ ${ }^{6}$ Department of Pathology, Kyung Hee University Hospital, \\ Kyung Hee University College of Medicine, Seoul, Republic of Korea
}

\begin{abstract}
Background/Aim: Mesonephric carcinoma (MNC) is a rare but notable entity of the female genital tract. While many researchers have acknowledged and studied MNC, much remains unknown on the characteristics of mesonephric remnant $(M N R)$ or hyperplasia $(M N H)$. There has not been any study examining the molecular features of MNR and $M N H$ so far. The aim of this study was to investigate the clinicopathological and molecular characteristics of ten uterine mesonephric lesions, including two MNRs without atypia, four MNHs without atypia, and three MNHs with atypia. Materials and Methods: We reviewed the electronic medical records and all available slides of ten cases from multiple institutions. Targeted sequencing and array
\end{abstract}

This article is freely accessible online.

Correspondence to: Hyun-Soo Kim, Department of Pathology and Translational Genomics, Samsung Medical Center, Sungkyunkwan University School of Medicine, 81, Irwon-ro, Gangnam-gu, Seoul 06351, Republic of Korea. Tel: +82 234101243, Fax: +82 234142831, e-mail: hyun-soo.kim@samsung.com; Kiyong Na, Department of Pathology, Kyung Hee University Hospital, Kyung Hee University College of Medicine, 26, Kyungheedae-ro, Dongdaemun-gu, Seoul 02447, Republic of Korea. Tel: +82 29588740, Fax: +82 29588744, e-mail: raripapa@gmail.com

Key Words: Uterus, cervix, atypical mesonephric hyperplasia, Kirsten rat sarcoma 2 viral oncogene homolog (KRAS) mutation, chromosome 1q gain. comparative genomic hybridization were performed. Results: Three atypical MNHs displayed nuclear enlargement, mild-tomoderate nuclear pleomorphism, and nuclear membrane irregularity, and harbored pathogenic Kirsten rat sarcoma 2 viral oncogene homolograt sarcoma 2 viral oncogene homolog (KRAS) mutation. Two of those that co-existed with $M N C$ harbored the same sequence alterations as each of their adjacent MNC. One of the three atypical MNHs harbored chromosome $1 q$ gain. Conclusion: Atypical MNH is a potential premalignant lesion in which KRAS mutation and chromosome $1 q$ gain play an important role in the early stage of mesonephric carcinogenesis.

The mesonephric duct is a precursor of the male genital tract present during human embryogenesis (1). In males, it gives rise to the internal genitalia, including the epididymides, vasa deferentia, seminal vesicles, and efferent ductules of the testes, whereas in females, it regresses with some remnants persisting in the broad ligament and the uterine cervix (2). Mesonephric remnant (MNR) and hyperplasia (MNH) are not uncommon findings in specimens of conizations and hysterectomies, being reported in up to one-third of resected adult uterine cervices (1). They might also be present within the wall of the vagina and uterine body, as well as the ovarian hilum and mesosalpinx (3).

Mesonephric carcinoma (MNC) is a rare malignant neoplasm thought to arise from the embryonal remnants of mesonephric tubules and ducts, comprising less than $1 \%$ of all gynecological tract malignancies (4). MNC arises 
typically in the uterine cervix and vagina, although some cases of mesonephric-like carcinoma (MLC) arising in the uterine body and ovary have been reported $(5,6)$. Despite the rarity of $\mathrm{MNC}$, its aggressive behavior and frequent distant metastasis compared to the more common types of uterine carcinoma warrant greater attention from the clinicians (6-9). MNC is also characterized by molecular aberrations that are significantly different from those found in other types of uterine carcinoma (10). MNC commonly harbors pathogenic mutations in Kirsten rat sarcoma 2 viral oncogene homolog $(K R A S)$ gene and gain of chromosome 1q. In contrast, tumor protein 53 (TP53) mutations are uncommon, and phosphatidylinositol-4,5-bisphosphate 3kinase catalytic subunit alpha $(P I K 3 C A)$ and phosphatase and tensin homolog deleted on chromosome 10 (PTEN) mutations have not been identified in MNC.

While many researchers have acknowledged and studied MNC, much remains unknown on the characteristics of uterine mesonephric lesions, including whether MNR or $\mathrm{MNH}$ is the precursor of MNC. Moreover, there has not been any study examining the molecular features of MNR and MNH. In this study, we analyzed the clinicopathological characteristics of uterine mesonephric lesions, particularly $\mathrm{MNH}$ with atypia, and investigated their association with MNC by examining these lesions at the molecular level as well as their morphologies.

\section{Materials and Methods}

Case selection. This study was reviewed and approved by the Institutional Review Board of Severance Hospital (Seoul, Republic of Korea) (4-2017-0968). Using the combination of keywords 'mesonephric' and 'hysterectomy', we extracted ten cases of MNR or MNH from surgical pathology archives of multiple institutions. All patients underwent hysterectomy for malignant (9/10) and premalignant (1/10) lesions of the female genital tract. Clinical information, including age of patients, reason for surgery (primary indication for surgical treatment), International Federation of Gynecology and Obstetrics (FIGO) stage $(11,12)$, and surgical procedure, was obtained from the electronic medical record system and pathology reports.

Pathological examination. Three board-certified pathologists (H.Y.W., K.N., and H.-S.K.) specialized in gynecological oncology reviewed all available hematoxylin and eosin-stained slides by light microscopy and determined the following details in the mesonephric lesions: size and extent of the mesonephric lesion, nuclear atypia (enlargement, pleomorphism, membrane irregularity, mitotic count, and atypical mitotic figure), architectural abnormalities (destructive stromal infiltration, confluent growth, back-to-back tubular arrangement, and cribriform pattern), and coagulative tumor cell necrosis. Based on the presence or absence of nuclear atypia, we classified the mesonephric lesions into the following four categories: MNR without atypia, MNR with atypia, MNH without atypia, and $\mathrm{MNH}$ with atypia. We performed this four-tiered categorization prior to conducting the ancillary tests, and chose representative slides for each case to perform immunostaining, targeted sequencing, and array comparative genomic hybridization (CGH).

Targeted sequencing. DNA and RNA were isolated from $10-\mu \mathrm{m}$ thick slices of formalin-fixed, paraffin-embedded (FFPE) tissue using a sterile 26-gauge needle and RecoverAll Multi-Sample RNA/DNA Isolation Workflow (Thermo Fisher Scientific, Waltham, MA, USA). The tumor tissue was obtained by manual microdissection and subjected to extraction of DNA and RNA for library preparation. The normal tissues of each case were obtained from the adjacent nonneoplastic area. DNA and RNA were quantified using the Qubit 2.0 Fluorometer (Thermo Fisher Scientific). DNA and RNA libraries were prepared as previously described $(6,13-22)$. These DNA libraries were generated from $20 \mathrm{ng}$ of DNA per sample using an Ion AmpliSeq Library Kit 2.0 (Thermo Fisher Scientific) and Oncomine Comprehensive Assay (OCA) v1 panel (Thermo Fisher Scientific). RNA libraries were generated from 15 ng of RNA per sample using the Ion AmpliSeq RNA Library Kit (Thermo Fisher Scientific). Libraries were quantified using the Ion Library Universal Quantification Kit (Thermo Fisher Scientific). The OCA v1 panel (Thermo Fisher Scientific) included 143 genes, of which 73 oncogenes were interrogated for mutational hotspots and 26 tumorsuppressor genes were interrogated for all exons. The panel provided the capability to detect copy number alterations (CNAs) in 49 genes and fusion drivers in 22 genes. The gene list is available at: https://www.thermofisher.com/kr/ko/home/clinical/preclinicalcompanion-diagnostic-development/oncomine-oncology/oncominecancer-research-panel-workflow.html. Consecutively, a $60 \mathrm{pmol} / 1$ pool of DNA:RNA libraries at a 4:1 ratio was used to prepare the templated Ion Sphere Particle (Thermo Fisher Scientific). Sequencing was performed using the Ion 540 Kit-Chef (Thermo Fisher Scientific) and Ion S5 system (Thermo Fisher Scientific). Sequencing data of approximately $200 \mathrm{bp}$ reads were generated after 500 flow runs.

Analysis of the sequencing data was performed using the Torrent Suite Software v5.2.2 (Thermo Fisher Scientific). This workflow was created by adding a custom hotspots Browser Extensible Data file to report mutations of interest and a custom CNA baseline (described below) using the manufacturer's default workflow as described previously $(13,14)$. The pipeline included signaling processing, base calling, quality score assignment, adapter trimming, read mapping to the human genome assembly GRCh37, quality control of mapping, coverage analysis with down-sampling, and variant calling. The identification of variants was performed using the Torrent Variant Caller plug-in and Ion Reporter Software v5.2 (Thermo Fisher Scientific). Coverage maps were generated using the Coverage Analysis plug-in (Thermo Fisher Scientific). Additionally, ANNOVAR (http://annovar.openbioinformatics.org/) was used for functional annotation of identified single nucleotide polymorphisms (SNPs) to investigate their genomic locations and variation (23). To eliminate error artifacts, sequence data were visually confirmed using the Integrative Genomics Viewer (Broad Institute, Cambridge, MA, USA). This workflow was able to report SNPs and indels in as low as $1 \%$ of the variant allele fraction. Based on the results of a feasibility study, the variant allele fraction threshold was established at 5\%. Copy number analysis was performed using the copy number module within the aforementioned workflow of the Ion Reporter Software v5.2 (Thermo Fisher Scientific). Copy numbers of 4 or greater were considered concordant if the orthogonal assay also reported a copy 
Kim et al: KRAS Mutation and 1q Gain in Atypical Mesonephric Hyperplasia

Table I. Clinicopathological characteristics of mesonephric remnants and hyperplasias.

\begin{tabular}{|c|c|c|c|c|c|c|c|c|c|c|c|}
\hline Category & $\begin{array}{c}\text { Case } \\
\text { no. }\end{array}$ & $\begin{array}{l}\text { Age } \\
\text { (yrs) }\end{array}$ & $\begin{array}{l}\text { Reason } \\
\text { for } \\
\text { surgery }\end{array}$ & $\begin{array}{l}\text { FIGO } \\
\text { stage }\end{array}$ & Surgery & $\begin{array}{l}\text { Size } \\
(\mathrm{mm})\end{array}$ & Extent & $\begin{array}{l}\text { Nuclear } \\
\text { enlargement }\end{array}$ & $\begin{array}{c}\text { Nuclear } \\
\text { pleo- } \\
\text { morphism }\end{array}$ & $\begin{array}{l}\text { Nuclear } \\
\text { membrane } \\
\text { irregularity }\end{array}$ & $\begin{array}{l}\text { Mitosis } \\
\text { (per } 10 \\
\text { HPFs) }\end{array}$ \\
\hline \multirow[t]{2}{*}{$\begin{array}{l}\text { MNR without } \\
\text { atypia }\end{array}$} & 1 & 61 & MNC, cervix & IB2 & $\begin{array}{c}\text { TH+BSO+ } \\
\text { PLND+PALND }\end{array}$ & 4 & Deep & Absent & Absent & Absent & 0 \\
\hline & 2 & 59 & $\begin{array}{l}\text { EC, grade } 2 \text {, } \\
\text { endometrium }\end{array}$ & II & $\begin{array}{c}\text { TH+BSO+ } \\
\text { PLND+PALND }\end{array}$ & 5 & Superficial & Absent & Absent & Absent & 0 \\
\hline \multirow{5}{*}{$\begin{array}{l}\text { MNH without } \\
\text { atypia }\end{array}$} & 3 & 56 & MNC, cervix & IB1 & $\mathrm{TH}+\mathrm{BSO}$ & 11 & Deep & Absent & Absent & Absent & 0 \\
\hline & 4 & 51 & U-EA, cervix & IB1 & $\mathrm{RH}+\mathrm{BSO}+\mathrm{PLND}$ & 11 & $\begin{array}{l}\text { Superficial } \\
\text { and deep }\end{array}$ & Absent & Absent & Absent & 0 \\
\hline & 5 & 55 & $\begin{array}{l}\text { EC, grade 1, } \\
\text { endometrium }\end{array}$ & IA & $\begin{array}{c}\text { TH+BSO+ } \\
\text { PLND+PALND }\end{array}$ & 7 & Superficial & Absent & Absent & Absent & 0 \\
\hline & 6 & 60 & $\begin{array}{l}\text { HGSC, grade } 3 \text {, } \\
\text { bilateral ovaries }\end{array}$ & IIIC & $\begin{array}{l}\text { TH+BSO+PLND+ } \\
\text { PALND+TOMT }\end{array}$ & 7 & Superficial & Absent & Absent & Absent & 0 \\
\hline & 7 & 55 & $\begin{array}{l}\text { HSIL (CIN 3), } \\
\text { cervix }\end{array}$ & NA & TH+LSO & 8 & Superficial & Absent & Absent & Absent & 0 \\
\hline \multirow[t]{3}{*}{$\begin{array}{l}\text { MNH with } \\
\text { atypia }\end{array}$} & 8 & 55 & PD-EA, cervix & IB1 & $\mathrm{RH}+\mathrm{BSO}+\mathrm{PLND}$ & 7 & Superficial & Present & $\begin{array}{l}\text { Mild to } \\
\text { moderate }\end{array}$ & Present & 0 \\
\hline & 9 & 54 & MNC, cervix & IIB & $\mathrm{TH}+\mathrm{BSO}$ & 12 & $\begin{array}{l}\text { Superficial } \\
\text { and deep }\end{array}$ & Present & $\begin{array}{l}\text { Mild to } \\
\text { moderate }\end{array}$ & Present & 1 \\
\hline & 10 & 55 & MNC, cervix & IVB & $\mathrm{TH}+\mathrm{RSO}$ & 11 & Superficial & Present & $\begin{array}{l}\text { Mild to } \\
\text { moderate }\end{array}$ & Present & 0 \\
\hline
\end{tabular}

MNR: Mesonephric remnant; MNH: mesonephric hyperplasia; MNC: mesonephric carcinoma; EC: endometrioid carcinoma; U-EA: usual-type endocervical adenocarcinoma; HGSC: high-grade serous carcinoma; HSIL: high-grade squamous intraepithelial lesion; CIN: cervical intraepithelial neoplasia; PD-EA: poorly differentiated endocervical adenocarcinoma; FIGO: International Federation of Gynecology and Obstetrics; NA: not applicable; TH: total hysterectomy; BSO: bilateral salpingo-oophorectomy; PLND: pelvic lymph node dissection; PALND: paraaortic lymph node dissection; RH: radical hysterectomy; LSO: left salpingo-oophorectomy; TOMT: total omentectomy; HPFs: high-power fields.

number of 4 or greater for target genes. Fusions were detected using the fusion detection module within the Ion Reporter Software (Thermo Fisher Scientific) workflow. This pipeline only reported fusions that were annotated previously, as defined in a reference file preloaded into the workflow $(13,14)$.

Array CGH. Both FFPE and reference DNA (NA10851) were labeled using an optimized version of the protocol for ULS labeling of FFPE DNA (Agilent Technologies, Santa Clara, CA, USA). Heat fragmentation at $95^{\circ} \mathrm{C}$ was required before labeling when the average fragment size was greater than $7.0 \mathrm{~kb}$. Accordingly, $500 \mathrm{ng}$ of FFPE DNA and reference DNA was then chemically labeled by incubating with ULS-Cy5 and Cy3, respectively, for $30 \mathrm{~min}$. Labeling reactions were prepared in thin-walled $0.2 \mathrm{ml}$ PCR tubes and incubated on a thermal cycler with a heated lid. Unreacted dye was then removed using KREApure filters (Agilent Technologies). DNA labeling efficiency was assessed by NanoDrop ND-2000 spectrophotometry (Thermo Fisher Scientific) measuring $A_{260}$ (for DNA), $\mathrm{A}_{550}$ (for $\mathrm{Cy} 5$ ), and $\mathrm{A}_{649}$ (for Cy3) values for the determination DNA and fluorophore concentrations. The degree of labeling (DoL) is represented by the number of fluorophore molecules per 100 nucleotides, expressed as a percentage and was calculated from the post-labeling DNA yield and concentration of fluorophores. According to the manufacturer's recommendations, DoL values between $0.75 \%$ and $2.5 \%$ were regarded as optimal for Cy5, whereas values between $1.75 \%$ and $3.5 \%$ were considered optimal for Cy3-labeled DNA.

\section{Results}

Clinical characteristics. Table I summarizes the clinicopathological characteristics of 10 patients with MNR or MNH. The patients' age ranged between 51 and 61 (mean=56.1) years. Primary indications for the surgical procedures yielding specimens were cervical MNC (4/10), endometrial endometrioid carcinoma (2/10), endocervical adenocarcinoma (2/10), ovarian high-grade serous carcinoma $(1 / 10)$, and cervical high-grade squamous intraepithelial lesion $(1 / 10)$. None of the patients had any history of oral contraceptive use, postmenopausal hormone replacement therapy, or preoperative chemotherapy.

All four patients with MNC (cases 1, 3, 9, and 10) were postmenopausal and presented with vaginal bleeding. At the time of initial diagnosis, the FIGO stages were IB1, IB2, IIB (parametrial involvement), and IVB (pulmonary metastasis), respectively.

Pathological characteristics. Ten cases were classified into two MNRs without atypia (cases 1 and 2), five MNHs without atypia (cases 3-7), and three MNHs with atypia (cases 8-10). None of the cases was classified as MNR with atypia. 



Figure 1. Histological features of mesonephric remnant without atypia. (A) Several small tubules are randomly scattered within the superficial cervical stroma. (B) Small tubules and mildly dilated tubules are distributed in linear arrays. $(C-D)$ The tubular structures contain dense $(C)$ or pale $(D)$ eosinophilic secretions within their lumina. (E-F) The lining epithelium is cuboidal-to-short columnar and bland. Nuclei are small and uniform without atypia.

MNR without atypia. Two MNRs were located in the deep and superficial cervical stroma, respectively. They consisted of clusters (Figure 1A), lobules, or linear arrays (Figure 1B) of small to medium-sized tubules, lined by bland cuboidal- to-columnar epithelial cells. Most of the mesonephric tubules contained dense (Figure 1C) or pale (Figure 1D) eosinophilic intraluminal secretions. Their nuclei were small and uniform (Figure 1E). Nuclear membrane irregularities were absent or 

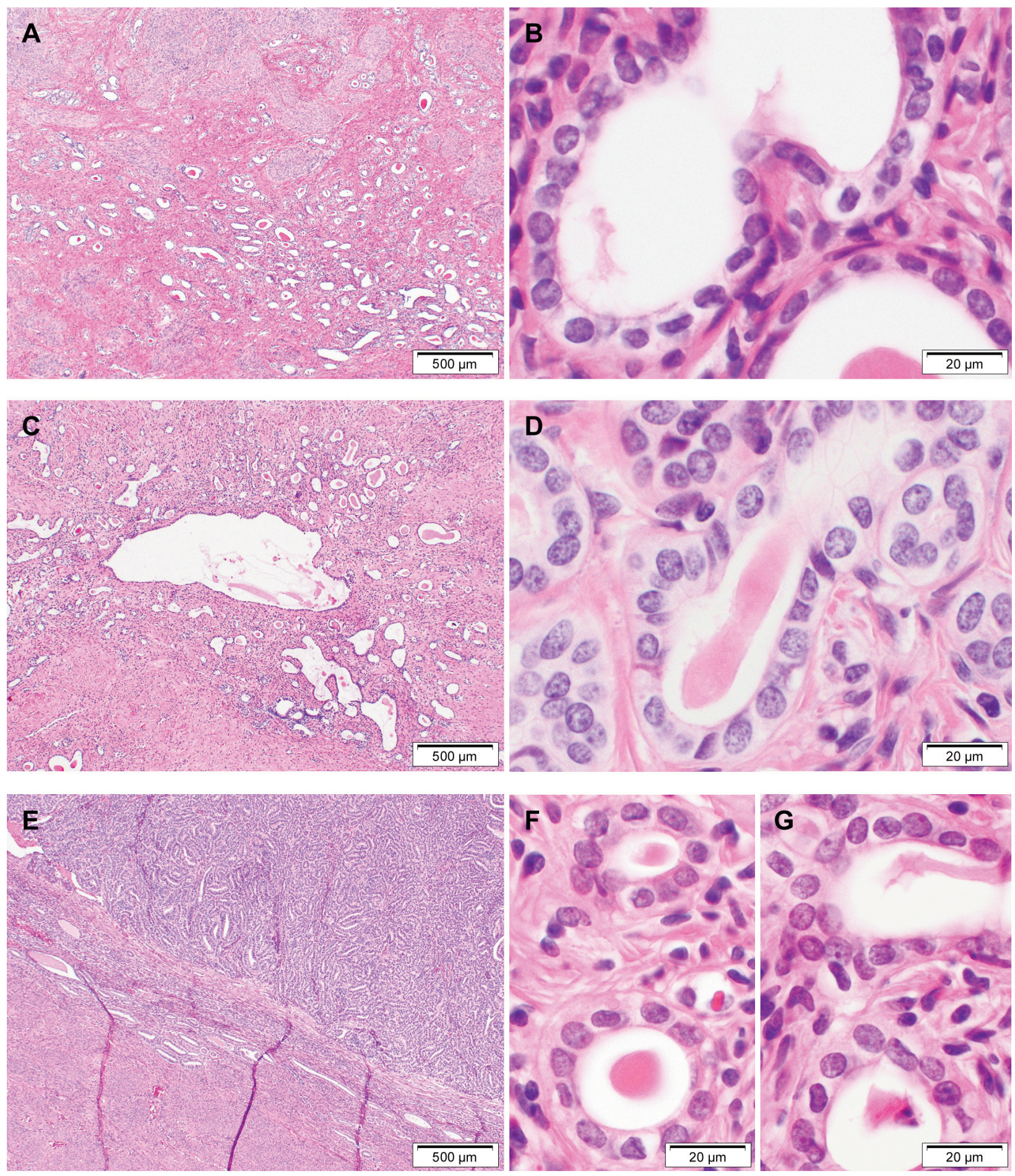

Figure 2. Histological features of mesonephric hyperplasia $(M N H)$ without atypia. (A) Diffuse tubular proliferation without lobular growth is noted. Proliferation of small mesonephric tubules and varying degrees of intervening stroma are observed. (B) Uniform and bland nuclei of MNH are similar to those of mesonephric remnant. (C) Simple small mesonephric tubules radially distributed around large central ducts display luminal dilatation, irregular shape, and haphazard arrangement, but lack architectural abnormalities. Dilated ducts contain nothing or a small amount of eosinophilic secretion, whereas most of the surrounding tubules possess deeply eosinophilic hyaline-like material. (D) The tubular epithelium does not exhibit nuclear atypia. (E) MNH is observed along the pushing border of mesonephric carcinoma. The surrounding tubules and ducts are compressed and stretched over the border. $(F-G)$ Nuclei of the lining epithelium are bland with minimal membrane irregularity. Intraluminal eosinophilic secretions are suggestive of their mesonephric origin. 
minimal, and intranuclear grooves were rarely observed (Figure 1F).

MNH without atypia. The histological features of five MNHs were similar to those of MNR, but the tubules and ducts were present in greater abundance and were larger than $6 \mathrm{~mm}(2,3$, 24,25 ). Two of the five cases (cases 4 and 5) displayed diffuse proliferation of mesonephric tubules with intervening stroma and without lobular or clustered growth (Figure 2A). Back-toback tubular arrangement or cribriform architecture was not observed. There was no nuclear atypia, architectural complexity, or mitotic activity (Figure 2B). Two cases (cases 6 and 7) showed a few central mesonephric ducts surrounded by arranged congeries of simple mesonephric tubules (Figure 2C). Most mesonephric tubules were occasionally irregularshaped and separated by varying amounts of intervening stroma. Elongated dilated ducts contained nothing or a small amount of eosinophilic secretions, whereas most randomly scattered tubules possessed deeply eosinophilic materials. The nuclei of tubules and ducts were clearly bland, without hyperchromasia, pleomorphism, stratification, or mitosis (Figure 2D). In the remaining one case (case 3), the lesion was located adjacent to the expanding edge of the MNC, resulting in the compression, atrophy, and stretch of the surrounding tubules over the relatively well-defined tumor border (Figure 2E). The nuclei of MNH were small and bland with round (Figures 2F-G) or elongated shapes, whereas those of MNC were large, hyperchromatic, and pleomorphic with irregular nuclear membranes and frequent mitotic figures.

MNH with atypia. We identified three cases (cases 8-10) of $\mathrm{MNH}$ showing nuclear atypia compared to the non-atypical MNH. These lesions did not exhibit any atypical mitotic figure, architectural abnormality, or coagulative tumor cell necrosis. Thus, we considered that overall histological features in these lesions were not sufficient for the diagnosis of MNC. Detailed descriptions of the histological features are as follows.

In case 8 , cystically dilated tubular proliferation was observed. Round or ovoid cystic structures were noted in the superficial cervical stroma, with small mesonephric tubules surrounding the cystic structures (Figure 3A). Some dilated tubules contained pale basophilic or mucoid secretions of lower density than those within the small tubules (Figure 3B). Complex glandular configurations were absent, and the intervening stroma was clearly observed. In contrast to cases 3-7, we noted a patchy distribution of nuclear atypia. Compared to the small and bland nuclei of the adjacent nonatypical tubules (Figure 3C), the nuclei of atypical mesonephric tubules displayed enlargement, mild-tomoderate pleomorphism, and irregular membrane (Figures 3D-E). High-power magnifications (Figure 3F-H) more clearly revealed that the nuclei were 1.5- to 3-times larger and more pleomorphic with irregular membranes than those of their non-atypical counterparts. Mitoses or atypical mitotic figures, as well as peritubular edema, inflammation, and necrosis, were absent.

In case 9, variable-sized cystic structures were randomly scattered at the periphery of the MNC (Figure 4A and B). The carcinoma cells showed tubular, endometrioid-like, cribriform, and glomeruloid architectures merged with round, ovoid, or irregular-shaped, cystically dilated tubules. Although some of these tubules exhibited the typical appearance of mesonephric tubules lined by cuboidal or flat epithelium and containing eosinophilic secretions (Figure 4C), many displayed nuclear atypia and stratification (Figure 4D). The nuclei were 1.5- to 2-times larger and showed mild-to-moderate pleomorphism and increased nuclear membrane irregularities than those of the non-atypical counterparts, displaying a morphology nearly identical to the nuclei of the adjacent MNC (Figure 4E). High-power magnifications (Figure 4F-H) displayed more clearly the enlarged nuclei with pleomorphism and irregular membranes in areas of atypical MNH and MNC compared with the nonatypical tubules. A single mitotic figure was detected in 10 high-power fields (Figure 4G). However, these atypical cells did not show any architectural complexity.

In case 10 , we noted a closely packed tubular arrangement present around the MNC. At low-power magnifications, the carcinoma area appeared deeply basophilic due to hypercellularity and nuclear hyperchromasia, whereas the $\mathrm{MNH}$ area appeared pale or lightly eosinophilic (Figure 5A and B). Despite numerous mesonephric tubules being crowded and haphazardly scattered, the intervening stroma was well preserved (Figure 5C). Some areas showed very small or poorly formed glandular spaces, while most of the tubular lumina were patent with eosinophilic secretions. As in case 9, the nuclei of atypical MNH exhibited enlargement, mild-tomoderate pleomorphism, membrane irregularities, and occasional intranuclear grooves (Figure 5D), and the degree of atypia observed in these nuclei was nearly identical to that displayed by nuclei of the adjacent carcinoma (Figure 5E). We could not detect any mitotic activity, atypical mitotic figure, or coagulative tumor cell necrosis, as well as architectural abnormality, in the areas of MNH. In contrast, the MNC showed obvious back-to-back tubular arrangement, loss of intervening stroma, and cribriform architecture. High-power magnifications of atypical MNH (Figure 5F) revealed nuclear atypia nearly identical to that of MNC (Figure 5G and $\mathrm{H}$ ).

Molecular characteristics. Both targeted sequencing and array $\mathrm{CGH}$ followed the histological classification of mesonephric lesions in four categories. Table II summarizes the results of targeted sequencing and array $\mathrm{CGH}$. We found that three MNHs with atypia harbored pathogenic missense mutations of the KRAS codon 12 , specifically, c. $35 \mathrm{G}>\mathrm{A}$ 


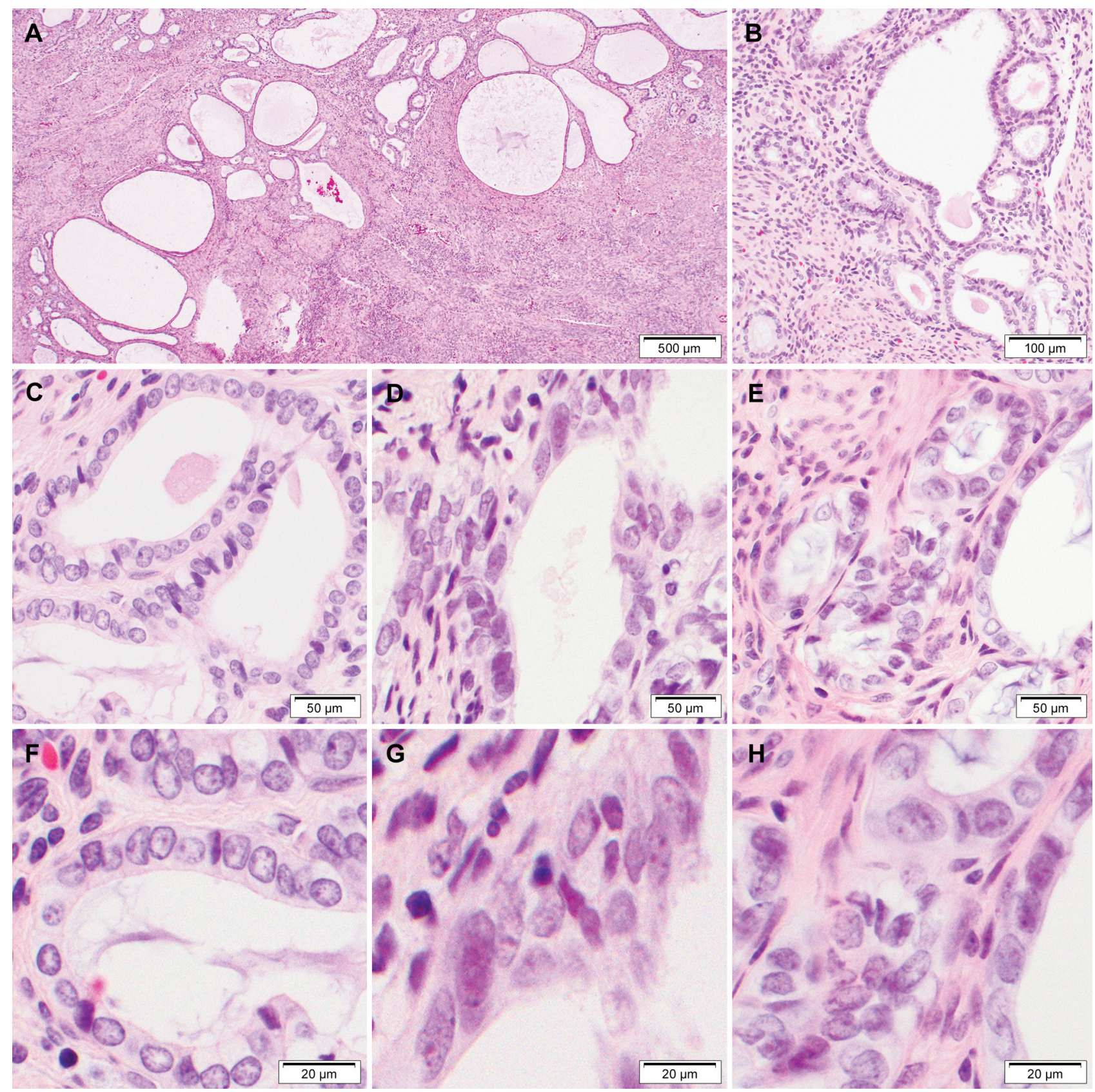

Figure 3. Histological features of mesonephric hyperplasia (MNH) with atypia (case 8). (A) Cystically dilated tubular structures are proliferating in linear arrays within the cervical stroma. Small tubules surround the dilated structures. (B) Eosinophilic secretions are observed in both small and dilated tubular lumina. No edema, inflammation, or fibrosis is observed in the peritubular stroma. $(C-E)$ Compared to the nuclei of $(C)$ non-atypical MNH, the nuclei of (D-E) atypical MNH are enlarged, pleomorphic, and exhibit membrane irregularities. $(F-H)$ High-power magnifications of images $C$-E. Nuclei of $(G$ and $H)$ atypical MNH were 1.5- to 3-times larger and possessed more irregular membrane than those of the $(F)$ non-atypical counterpart.

(p.G12D; case 8), c.34G>T (p.G12C; case 9), and c.35G>T (p.G12V; case 10). In two MNCs that co-existed with MNH with atypia (cases 9 and 10), the same type of KRAS mutation was identified (c.34G $>\mathrm{T}$ and c.35G $>\mathrm{T}$, respectively). In contrast, there was no pathogenic mutation in one MNR (case 1) found along with MNC. The remaining cases, consisting of one MNR without atypia and five MNHs without atypia, had wild-type $K R A S$. 

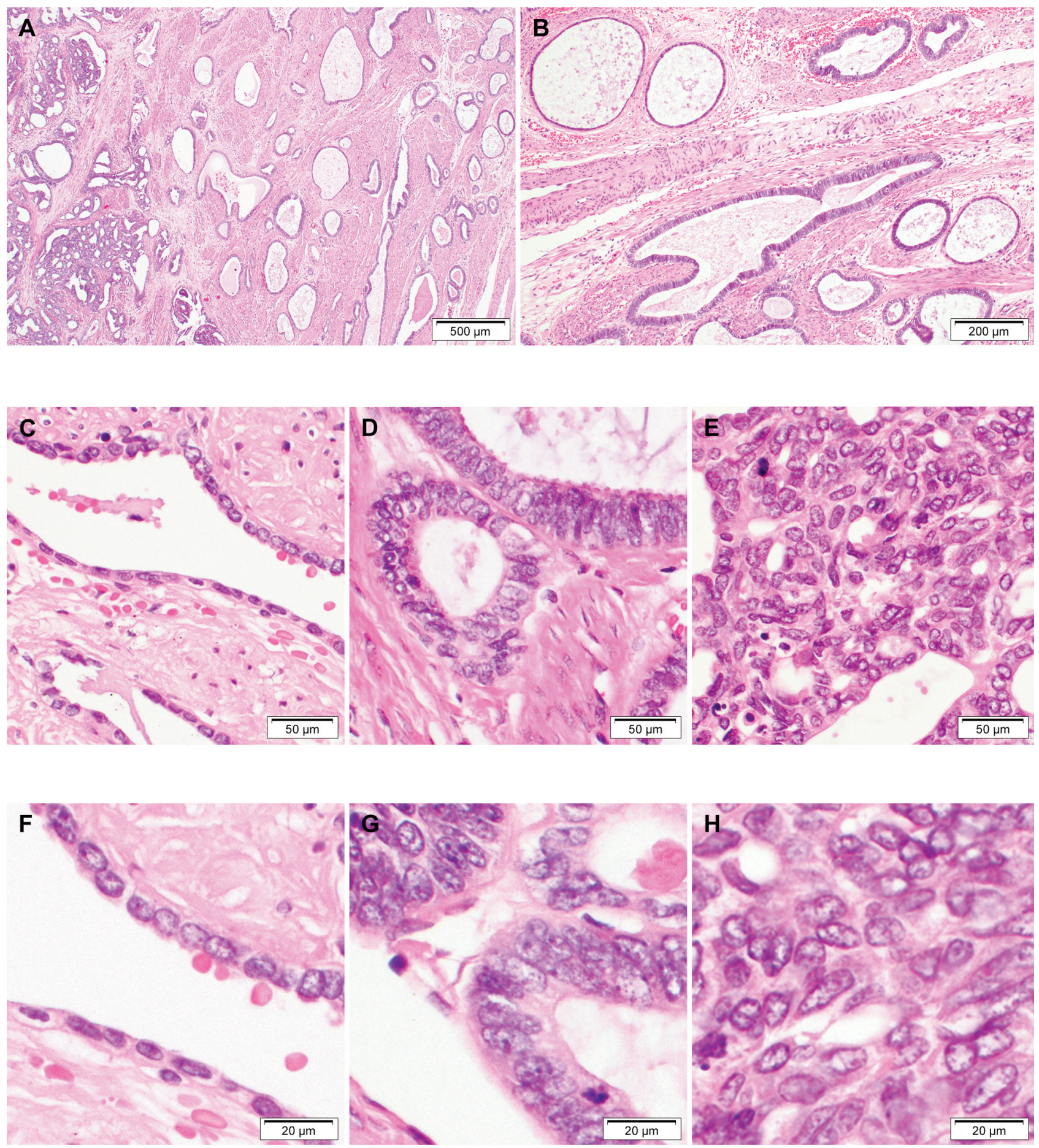

Figure 4. Histological features of mesonephric hyperplasia (MNH) with atypia (case 9). (A) Cystically dilated ductal structures (left and middle one-thirds) are observed at the periphery of mesonephric carcinoma (right one-third). Randomly scattered spaces of various shapes and sizes are observed. (B) Round, ovoid, or irregular-shaped cystically dilated tubules do not show architectural complexity. A difference in epithelial thickness between non-atypical and atypical tubules is noted. (C) Non-atypical MNH shows low cuboidal-to-flattened epithelium with small and bland nuclei. (D) The lining epithelium of atypical MNH is thicker than that of the non-atypical counterpart due to nuclear enlargement and stratification. No stromal desmoplasia or inflammation is observed. (E) Most nuclei observed in mesonephric carcinoma display mild atypia very similar to that of the atypical MNH. A single mitotic figure is detected (left upper corner). (F-H) High-power magnifications of images $C$-E. The nuclei of $(G)$ atypical MNH demonstrate enlargement and irregular membrane. A single mitotic figure is detected (right lower corner). 


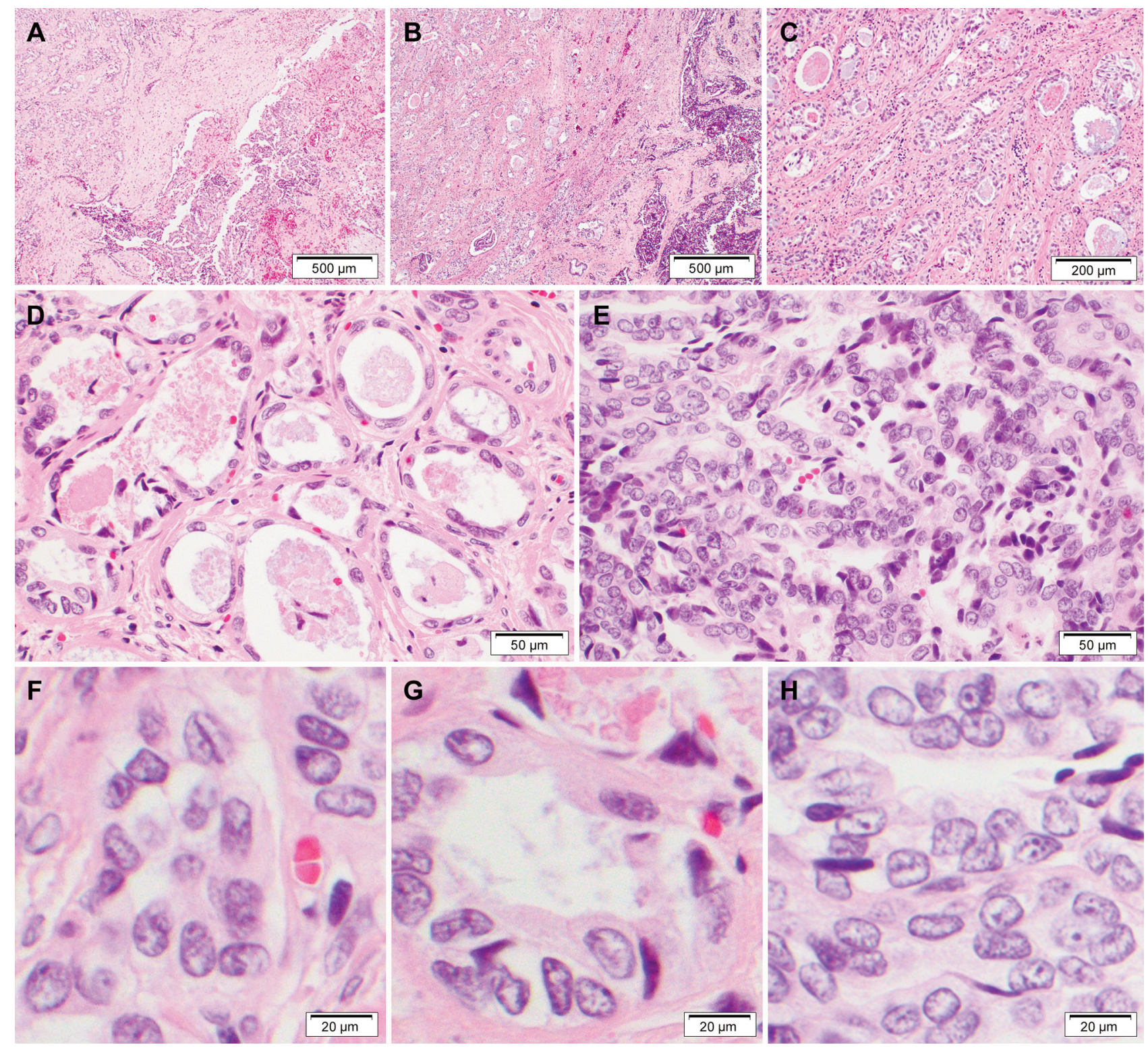

Figure 5. Histological features of mesonephric hyperplasia (MNH) with atypia (case 10). (A) At low-power magnification, atypical MNH (left upper corner) appears pale compared to the hyperchromatic mesonephric carcinoma (MNC; middle and left one-thirds). (B) In another area, atypical $M N H$ (middle and left two-thirds) appears lighter compared to the deeply basophilic MNC (right one-third). (C) Tubular lumina and intraluminal secretions are patent in atypical MNH. (D) Although numerous mesonephric tubules are crowded, the intervening cervical stroma is well preserved. (E) In contrast, MNC displays significant hypercellularity and back-to-back tubular arrangement. $(F-H)$ High-power magnifications of images $D$ and $E$. $(F$ and $G)$ The tubular epithelial cells show nuclear atypia including enlargement, significant membrane irregularity, and intranuclear grooves. $(H)$ The degree of atypia observed in the nuclei of adjacent MNC is nearly identical to that of the atypical MNH.

Copy number plots obtained by array CGH are shown in Figure 6. All of the two MNRs, five MNHs without atypia, and two of the three MNHs with atypia did not show any CNA. In contrast, one MNH with atypia (case 9) showed chromosome 1q gain, and four MNCs showed aberrations in multiple chromosomes (Table III). The most common alterations observed in MNCs were the gains of chromosome 1q (4/4) and 10 (4/4), followed by gains of chromosome 2 $(3 / 4), 12(3 / 4)$, and $20(3 / 4)$. We also observed the gains of chromosome $7(1 / 4), 16(2 / 4)$, and 17 (1/4) in MNCs. 


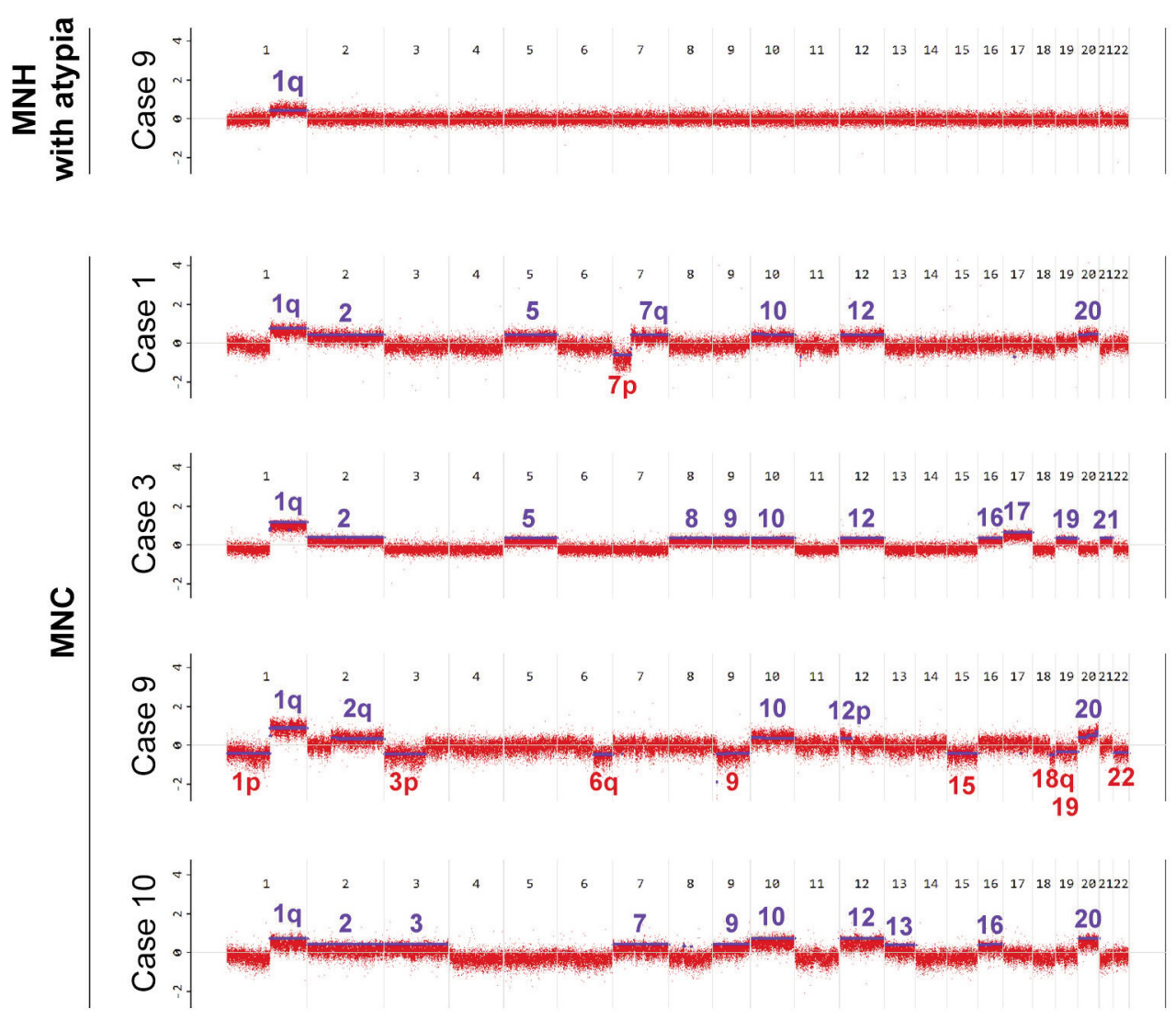

Figure 6. Copy number plots of atypical mesonephric hyperplasia (MNH; case 9) and mesonephric carcinomas (MNCs; cases 1, 3, 9, and 10). Copy number variations are indicated in blue or red for gain or loss in copy number, respectively.

\section{Discussion}

Ten cases of MNRs and MNHs were explored in search for their clinical and pathological significance. Based on the histological features reported in previous studies $(2,26)$, we classified the ten cases according to the presence or absence of nuclear atypia. Two cases were MNR without atypia; five were $\mathrm{MNH}$ without atypia; and three were $\mathrm{MNH}$ with atypia. Among these, we focused on the MNHs with atypia, i.e., atypical MNH. Despite the fact that these lesions have been acknowledged by only two studies $(2,26)$, it was evidently shown that these lesions were insufficient to call a carcinoma while being clearly different from MNHs and MNRs without atypia. Atypical MNH exhibited nuclear enlargement, mildto-moderate pleomorphism, and irregular membrane in comparison with the non-atypical counterpart. While so, the atypical MNH cases did not possess the architectural abnormalities of MNC (destructive stromal infiltration, confluent growth, back-to-back tubular arrangement, and cribriform pattern), malignant nuclear features (severe nuclear pleomorphism, increased mitotic activity, and atypical mitotic figure), and coagulative tumor cell necrosis.

In one of the two reports that studied MNH with atypia, Ayroud et al. (26) observed florid tubular and ductular structures in the endocervical mucosa, differing from but intermingled with the endocervical glands. They noted that their intraluminal secretions with eosinophilia had similar characteristics to those of the adjacent MNR. Upon careful histological examination and exclusion of mesonephric and endocervical adenocarcinomas, the authors concluded that the florid tubular structures were hyperplasia with atypia rather than carcinoma, hence the term "atypical" or "florid" $\mathrm{MNH}$. In another study, Ferry and Scully (2) openly stated that the division between MNC and MNH was arbitrary. Nevertheless, they pointed out that in the absence of clear diagnostic features of malignancy, the next step to detect the presence of MNC would be back-to-back glandular aggregation and disorderly invasion. The following step would be to identify cases with MNH appearing "predominantly typical, with only focal glandular crowding 
Table II. Molecular characteristics of mesonephric remnants and hyperplasias.

\begin{tabular}{|c|c|c|c|c|c|c|}
\hline \multirow[t]{2}{*}{ Category } & \multirow{2}{*}{$\begin{array}{c}\text { Case } \\
\text { no. }\end{array}$} & \multicolumn{4}{|c|}{ Single nucleotide variation } & \multirow[t]{2}{*}{ Copy number alteration } \\
\hline & & Gene & Mutation type & Sequence change & Predicted effect & \\
\hline \multirow[t]{2}{*}{ MNR without atypia } & 1 & Not detected & & & & Not detected \\
\hline & 2 & Not detected & & & & Not detected \\
\hline \multirow[t]{5}{*}{ MNH without atypia } & 3 & Not detected & & & & Not detected \\
\hline & 4 & Not detected & & & & Not detected \\
\hline & 5 & Not detected & & & & Not detected \\
\hline & 6 & Not detected & & & & Not detected \\
\hline & 7 & Not detected & & & & Not detected \\
\hline \multirow[t]{3}{*}{ MNH with atypia } & 8 & KRAS & Missense & c. $35 \mathrm{G}>\mathrm{A}$ & p.G12D & Not detected \\
\hline & 9 & KRAS & Missense & c. $34 \mathrm{G}>\mathrm{T}$ & p.G12C & Gain of chromosome 1q \\
\hline & 10 & $K R A S$ & Missense & c. $35 \mathrm{G}>\mathrm{T}$ & p.G12V & Not detected \\
\hline
\end{tabular}

MNR: Mesonephric remnant; MNH: mesonephric hyperplasia.

Table III. Molecular characteristics of mesonephric carcinoma.

\begin{tabular}{|c|c|c|c|c|c|c|}
\hline \multirow[t]{2}{*}{ Category } & \multirow{2}{*}{$\begin{array}{c}\text { Case } \\
\text { no. }\end{array}$} & \multicolumn{4}{|c|}{ Single nucleotide variation } & \multirow[t]{2}{*}{ Copy number alteration } \\
\hline & & Gene & Mutation type & Sequence change & Predicted effect & \\
\hline \multirow[t]{5}{*}{ MNC } & 1 & $K R A S$ & Missense & c. $34 \mathrm{G}>\mathrm{T}$ & p.G12C & $\begin{array}{l}\text { Gain: } 1 \mathrm{q}, \operatorname{chr} 2, \operatorname{chr} 5,7 \mathrm{q}, \\
\text { chr } 10, \operatorname{chr} 12, \operatorname{chr} 20\end{array}$ \\
\hline & & PIK3CA & Missense & c. $278 \mathrm{G}>\mathrm{A}$ & p.R93Q & Loss: $7 \mathrm{p}$ \\
\hline & 3 & $K R A S$ & Missense & c. $35 \mathrm{G}>\mathrm{T}$ & p.G12V & $\begin{array}{c}\text { Gain: } 1 \mathrm{q}, \operatorname{chr} 2, \operatorname{chr} 5 \\
\operatorname{chr} 8, \operatorname{chr} 9, \operatorname{chr} 10, \operatorname{chr} 12 \\
\operatorname{chr} 16, \operatorname{chr} 17, \operatorname{chr} 19, \operatorname{chr} 2\end{array}$ \\
\hline & 9 & $K R A S$ & Missense & c. $34 \mathrm{G}>\mathrm{T}$ & p.G12C & $\begin{array}{c}\text { Gain: } 1 \mathrm{q}, 2 \mathrm{q}, \operatorname{chr} 10 \\
12 \mathrm{p}, \operatorname{chr} 20 \\
\text { Loss: } 1 \mathrm{p}, 3 \mathrm{p}, 6 \mathrm{q}, \operatorname{chr} 9 \\
\text { chr } 15,18 \mathrm{q}, \operatorname{chr} 19, \operatorname{chr} 22\end{array}$ \\
\hline & 10 & $K R A S$ & Missense & c. $35 \mathrm{G}>\mathrm{T}$ & p.G12V & $\begin{array}{c}\text { Gain: } 1 \text { q, chr } 2, \operatorname{chr} 3, \\
\text { chr } 7, \operatorname{chr} 9, \operatorname{chr} 10, \operatorname{chr} 12, \\
\text { chr } 13, \operatorname{chr} 16, \operatorname{chr} 20\end{array}$ \\
\hline
\end{tabular}

MNC: Mesonephric carcinoma.

and nuclear atypia," and call them $M N H$ with atypia rather than carcinoma. The histological features we identified in our cases were concordant with those reported in these studies.

Thus, bringing together the histological analyses from previous studies and our study, we suggest to call these lesions atypical MNH defined by: the proliferation of mesonephric tubules or ducts, or both where 1) epithelial cells have nuclear atypia (e.g., mild-to-moderate pleomorphism, larger nuclei, and more nuclear membrane irregularities) than those of the adjacent non-atypical MNH, and where 2) epithelial cells do not form architectural abnormalities, such as destructive stromal infiltration, confluent growth, back-to-back glandular arrangement, and cribriform pattern.
All three atypical MNHs were studied at the molecular level for the first time to reveal some significant results. All of them harbored KRAS mutations, of which the type observed in these lesions were the same as those detected in the co-existing MNCs. In addition, one of the atypical MNH exhibited chromosome 1q gain, which was also found in the adjacent MNC amidst its other numerous mutations. The mutation of KRAS and the gain of chromosome 1q have been well acknowledged in MNC. Several targeted sequencing analyses from the past have shown that KRAS is the most common molecular abnormality in MNCs and MLCs. All 10 cases of MLC recently reported by Kolin et al. (27), Liang et al. (28), and Horn et al. (29) showed either p.G12V or p.G12D alterations. In larger cohorts, such as those reported 
by Mirkovic et al. (10), Euscher et al. (8), and our group (6), the majority of MNCs (9/13) and MLCs (25/30) harbored KRAS mutations. The second most common alteration in MNC was the gain of 1q. Nine of the 13 MNCs and 16 of the 17 MLC reported by Mirkovic et al. (10), Kolin et al. (27), and our group (6) harbored 1q gain. Consistent with these data, all four cases of MNC in this study harbored both KRAS mutations and 1q gain. Our observations regarding the $K R A S$ mutation and chromosome 1q gain in atypical $\mathrm{MNH}$ indicate that it could be a clonal lesion, and these two genetic alterations might be early events during the mesonephric carcinogenesis.

Mutations of KRAS result in constitutive activation of mitogen-activated protein kinase, which subsequently activates various downstream targets, leading to expression of genes involved in cellular proliferation, differentiation, and survival $(10,30,31)$. Activating $K R A S$ mutations have been detected in many human malignancies, particularly in pancreatic, colorectal, and pulmonary carcinomas, but also in endometrial and endocervical adenocarcinomas (32-36). At the early stage of carcinogenesis, the precancerous cells require $K R A S$ for survival. KRAS activity is also necessary to continue the neoplastic transformation and the regulation of cellular differentiation, indicating that KRAS mutations are important not only for tumor formation but also during early stages of tumor progression (37). Our observation of pathogenic mutations in codon 12 of the KRAS gene in all atypical MNHs and in none of MNHs without atypia suggest that KRAS mutation is one of the early events during the mesonephric carcinogenesis.

1q gain is considered one of the early changes occurring in mammary carcinogenesis since they have been detected as the sole chromosomal abnormality in well-differentiated breast carcinoma with a few alterations $(38,39)$. These genetic changes and the resulting chromosome imbalances have been thought to play a pathogenic role in breast carcinoma development. Similarly, 1q gain is one of the most common cytogenetic abnormalities in patients with multiple myeloma, occurring in approximately $40 \%$ of patients (40, 41). 1q gain occurs with disease progression in multiple myeloma, often by jumping translocations. The copy number can increase over time, with higher rates of 1q gain detection after progression from precursor conditions including monoclonal gammopathy of undetermined significance and smoldering multiple myeloma $(41,42)$. In addition, 1q gain is associated with increased risk of relapse and adverse outcome in patients with favorable-histology Wilms' tumor (43). CNA in malignant mesonephric lesions were primarily at the chromosome or arm level, without distinct copy number changes. In our previous study, 1q gain was the most common CNA detected in $91.7 \%$ of MLCs (6). Based on the previous data that the majority of MNCs and MLCs harbored 1q gain and on our observations that 1q gain was the only chromosomal abnormality in atypical MNHs, we suggest that this alteration is one of the early stage events of mesonephric carcinogenesis.

In 2017, a report by Mirkovic et al. (25) suggested that $\mathrm{MNH}$ might not be neoplastic. In their case series, none of the $10 \mathrm{MNH}$ harbored mutations in KRAS. However, because they do not describe any atypical $\mathrm{MNH}$, we believe that their argument does not oppose ours. In agreement with their data, all five MNHs without atypia in our series did not harbor any KRAS mutation or CNA.

In conclusion, we demonstrated three cases of $\mathrm{MNH}$ showing mild-to-moderate nuclear pleomorphism, nuclear enlargement, and irregular nuclear membranes compared to the adjacent non-atypical MNH. These atypical MNHs displayed mild to moderate nuclear atypia, the degree of which was similar to that of the adjacent MNC, but without any architectural abnormality. All three atypical MNHs were found to harbor KRAS mutations, and one of them also exhibited chromosome 1q gain. Both the pathogenic mutations in KRAS and gain of 1q were observed in all MNC examined. In contrast, none of the MNRs or MNHs without atypia was shown to have pathogenic mutations or chromosomal aberrations. These findings raise the possibility that atypical $\mathrm{MNH}$ is potentially a premalignant lesion of MNC, and that $K R A S$ mutation and 1q gain are early events during mesonephric carcinogenesis.

\section{Conflicts of Interest}

None of the Authors has any conflict of interest to declare.

\section{Authors' Contributions}

All Authors made substantial contributions to the conceptualization and design of the study; the acquisition, analysis, curation, and interpretation of the data; drafting of the manuscript; critical revision and editing of the manuscript for important intellectual content; and the approval of the final version to be published.

\section{Acknowledgments}

This research was supported by the Basic Science Research Program through the National Research Foundation of Korea (NRF) funded by the Ministry of Education (2016R1D1A1B03935584) and by the NRF funded by the Korean government (Ministry of Science and ICT) (2018R1C1B5043725).

\section{References}

1 Goyal A and Yang B: Differential patterns of PAX8, p16, and ER immunostains in mesonephric lesions and adenocarcinomas of the cervix. Int J Gynecol Pathol 33: 613-619, 2014. PMID: 25272301. DOI: 10.1097/PGP.0000000000000102

2 Ferry JA and Scully RE: Mesonephric remnants, hyperplasia, and neoplasia in the uterine cervix. A study of 49 cases. Am J 
Surg Pathol 14: 1100-1111, 1990. PMID: 2252101. DOI: 10.1097/00000478-199012000-00002

3 Howitt BE and Nucci MR: Mesonephric proliferations of the female genital tract. Pathology 50: 141-150, 2018. PMID: 29269124. DOI: 10.1016/j.pathol.2017.11.084

4 Kezlarian B, Muller S, Werneck Krauss Silva V, Gonzalez C, Fix DJ, Park KJ and Murali R: Cytologic features of upper gynecologic tract adenocarcinomas exhibiting mesonephric-like differentiation. Cancer Cytopathol 127: 521-528, 2019. PMID: 31318491. DOI: $10.1002 /$ cncy. 22160

5 McFarland M, Quick CM and McCluggage WG: Hormone receptor-negative, thyroid transcription factor 1-positive uterine and ovarian adenocarcinomas: report of a series of mesonephriclike adenocarcinomas. Histopathology 68: 1013-1020, 2016. PMID: 26484981. DOI: 10.1111/his.12895

$6 \mathrm{Na} \mathrm{K}$ and Kim HS: Clinicopathologic and molecular characteristics of mesonephric adenocarcinoma arising from the uterine body. Am J Surg Pathol 43: 12-25, 2019. PMID: 29189288. DOI: 10.1097/PAS.0000000000000991

7 Dierickx A, Goker M, Braems G, Tummers P and Van den Broecke R: Mesonephric adenocarcinoma of the cervix: case report and literature review. Gynecol Oncol Rep 17: 7-11, 2016. PMID: 27354991. DOI: 10.1016/j.gore.2016.05.002

8 Euscher ED, Bassett R, Duose DY, Lan C, Wistuba I, Ramondetta L, Ramalingam P and Malpica A: Mesonephric-like carcinoma of the endometrium: a subset of endometrial carcinoma with an aggressive behavior. Am J Surg Pathol 44: 429-443, 2020. PMID: 31725471. DOI: 10.1097/PAS.0000000000001401

9 Yap OW, Hendrickson MR, Teng NN and Kapp DS: Mesonephric adenocarcinoma of the cervix: a case report and review of the literature. Gynecol Oncol 103: 1155-1158, 2006. PMID: 17023031. DOI: 10.1016/j.ygyno.2006.08.031

10 Mirkovic J, Sholl LM, Garcia E, Lindeman N, MacConaill L, Hirsch M, Dal Cin P, Gorman M, Barletta JA, Nucci MR, McCluggage WG and Howitt BE: Targeted genomic profiling reveals recurrent $K R A S$ mutations and gain of chromosome 1q in mesonephric carcinomas of the female genital tract. Mod Pathol 28: 1504-1514, 2015. PMID: 26336887. DOI: 10.1038/modpathol.2015.103

11 Oncology FCoG: FIGO staging for carcinoma of the vulva, cervix, and corpus uteri. Int J Gynaecol Obstet 125: 97-98, 2014. PMID: 24630859. DOI: 10.1016/j.ijgo.2014.02.003

12 Bhatla N, Berek JS, Cuello Fredes M, Denny LA, Grenman S, Karunaratne K, Kehoe ST, Konishi I, Olawaiye AB, Prat J, Sankaranarayanan R, Brierley J, Mutch D, Querleu D, Cibula D, Quinn M, Botha H, Sigurd L, Rice L, Ryu HS, Ngan H, Maenpaa J, Andrijono A, Purwoto G, Maheshwari A, Bafna UD, Plante M and Natarajan J: Revised FIGO staging for carcinoma of the cervix uteri. Int J Gynaecol Obstet 145: 129-135, 2019. PMID: 30656645. DOI: 10.1002/ijgo.12749

13 Hovelson DH, McDaniel AS, Cani AK, Johnson B, Rhodes K, Williams PD, Bandla S, Bien G, Choppa P, Hyland F, Gottimukkala R, Liu G, Manivannan M, Schageman J, Ballesteros-Villagrana E, Grasso CS, Quist MJ, Yadati V, Amin A, Siddiqui J, Betz BL, Knudsen KE, Cooney KA, Feng FY, Roh MH, Nelson PS, Liu CJ, Beer DG, Wyngaard P, Chinnaiyan AM, Sadis S, Rhodes DR and Tomlins SA: Development and validation of a scalable next-generation sequencing system for assessing relevant somatic variants in solid tumors. Neoplasia 17: 385-399, 2015. PMID: 25925381. DOI: 10.1016/j.neo.2015.03.004
14 Jeon J, Maeng LS, Bae YJ, Lee EJ, Yoon YC and Yoon N: Comparing clonality between components of combined hepatocellular carcinoma and cholangiocarcinoma by targeted sequencing. Cancer Genomics Proteomics 15: 291-298, 2018. PMID: 29976634. DOI: $10.21873 / \operatorname{cgp} .20087$

15 Kim JY, Kim SH and Kim HS: Promoter methylation downregulates osteoprotegerin expression in ovarian carcinoma. Anticancer Res 39: 2361-2367, 2019. PMID: 31092428. DOI: 10.21873/anticanres. 13353

16 Kim JS, Choi YS, Park JH, Yun J, Kim S, Lee JH, Yun BH, Park JH, Seo SK, Cho S, Kim HS and Lee BS: Role of B-cell translocation gene 1 in the pathogenesis of endometriosis. Int $\mathrm{J}$ Mol Sci 20: 3372, 2019. PMID: 31324015. DOI: 10.3390/ijms20133372

17 Kim HN, Woo HY, Do SI and Kim HS: Targeted sequencing of tubo-ovarian and peritoneal high-grade serous carcinoma with wild-type p53 immunostaining pattern. In Vivo 33: 1485-1492, 2019. PMID: 31471396 . DOI: 10.21873 /invivo.11628

18 Jung YY, Woo HY and Kim HS: Targeted genomic sequencing reveals novel TP53 in-frame deletion mutations leading to p53 overexpression in high-grade serous tubo-ovarian carcinoma. Anticancer Res 39: 2883-2889, 2019. PMID: 31177126. DOI: 10.21873/anticanres. 13417

19 Bae GE, Yoon N, Cho EY, Kim HS and Cho SY: Clinicopathological and molecular characteristics of mammary adenoid cystic carcinoma with adipocytic differentiation with emphasis on the identification of a novel BRAF mutation. Anticancer Res 39: 369-374, 2019. PMID: 30591482. DOI: 10.21873/anticanres.13121

20 Sung JY, Jung YY and Kim HS: Clinicopathological characteristics and KRAS mutation status of endometrial mucinous metaplasia and carcinoma. Anticancer Res 38: 27792786, 2018. PMID: 29715099. DOI: 10.21873/anticanres.12521

$21 \mathrm{Na}$ K, Sung JY and Kim HS: TP53 mutation status of tuboovarian and peritoneal high-grade serous carcinoma with a wildtype p53 immunostaining pattern. Anticancer Res 37: 66976703, 2017. PMID: 29187446. DOI: 10.21873/anticanres.12128

$22 \mathrm{Na}$ K, Kim EK, Jang W and Kim HS: CTNNB1 mutations in ovarian microcystic stromal tumors: identification of a novel deletion mutation and the use of pyrosequencing to identify reported point mutation. Anticancer Res 37: 3249-3258, 2017. PMID: 28551672. DOI: 10.21873/anticanres.11688

23 Yang $\mathrm{H}$ and Wang $\mathrm{K}$ : Genomic variant annotation and prioritization with ANNOVAR and wANNOVAR. Nat Protoc 10: 1556-1566, 2015. PMID: 26379229. DOI: 10.1038/ nprot.2015.105

24 Jones MA, Andrews J and Tarraza HM: Mesonephric remnant hyperplasia of the cervix: a clinicopathologic analysis of 14 cases. Gynecol Oncol 49: 41-47, 1993. PMID: 8482559. DOI: 10.1006/gyno.1993.1083

25 Mirkovic J, Schoolmeester JK, Campbell F, Miron A, Nucci MR and Howitt BE: Cervical mesonephric hyperplasia lacks KRAS/NRAS mutations. Histopathology 71: 1003-1005, 2017. PMID: 28703285. DOI: 10.1111/his.13307

26 Ayroud Y, Gelfand MM and Ferenczy A: Florid mesonephric hyperplasia of the cervix: a report of a case with review of the literature. Int J Gynecol Pathol 4: 245-254, 1985. PMID: 2414240. DOI: $10.1097 / 00004347-198509000-00009$

27 Kolin DL, Costigan DC, Dong F, Nucci MR and Howitt BE: A combined morphologic and molecular approach to retrospectively 
identify $K R A S$-mutated mesonephric-like adenocarcinomas of the endometrium. Am J Surg Pathol 43: 389-398, 2019. PMID: 30489318. DOI: 10.1097/PAS.0000000000001193

28 Liang Y, Shi H, Zhu X, Yu M and Zhang X: Mesonephric adenocarcinoma of the uterine corpus: a report on 2 cases with comparison to its cervical counterpart. Int J Gynecol Pathol, 2020. PMID: 31985582. DOI: 10.1097/PGP.0000000000000639

29 Horn LC, Hohn AK, Krucken I, Stiller M, Obeck U and Brambs CE: Mesonephric-like adenocarcinomas of the uterine corpus: report of a case series and review of the literature indicating poor prognosis for this subtype of endometrial adenocarcinoma. J Cancer Res Clin Oncol 146: 971-983, 2020. PMID: 31927619. DOI: $10.1007 / \mathrm{s} 00432-019-03123-7$

30 Olson JM and Hallahan AR: p38 MAP kinase: a convergence point in cancer therapy. Trends Mol Med 10: 125-129, 2004. PMID: 15102355. DOI: 10.1016/j.molmed.2004.01.007

31 Peyssonnaux $\mathrm{C}$ and Eychene A: The Raf/MEK/ERK pathway: new concepts of activation. Biol Cell 93: 53-62, 2001. PMID: 11730323. DOI: $10.1016 / \mathrm{s} 0248-4900(01) 01125-\mathrm{x}$

32 Jancik S, Drabek J, Radzioch D and Hajduch M: Clinical relevance of KRAS in human cancers. J Biomed Biotechnol 2010: 150960, 2010. PMID: 20617134. DOI: $10.1155 / 2010 / 150960$

33 Hodgson A, Amemiya Y, Seth A, Cesari M, Djordjevic B and Parra-Herran C: Genomic abnormalities in invasive endocervical adenocarcinoma correlate with pattern of invasion: biologic and clinical implications. Mod Pathol 30: 1633-1641, 2017. PMID: 28731050. DOI: $10.1038 /$ modpathol.2017.80

34 Sideris M, Emin EI, Abdullah Z, Hanrahan J, Stefatou KM, Sevas V, Emin E, Hollingworth T, Odejinmi F, Papagrigoriadis $\mathrm{S}$, Vimplis $\mathrm{S}$ and Willmott $\mathrm{F}$ : The role of KRAS in endometrial cancer: a mini-review. Anticancer Res 39: 533-539, 2019. PMID: 30711927. DOI: 10.21873/anticanres.13145

35 Ring KL, Yates MS, Schmandt R, Onstad M, Zhang Q, Celestino J, Kwan SY and Lu KH: Endometrial cancers with activating KRAS mutations have activated estrogen signaling and paradoxical response to MEK inhibition. Int J Gynecol Cancer 27: 854-862, 2017. PMID: 28498246. DOI: 10.1097/IGC.000 0000000000960

36 Jackson CL, Hang S, Hansen K, He M, Sung CJ, Quddus MR, Xiong M, Wang Y, Patel NR, Lawrence WD and Xiong J: Endometrial adenocarcinomas with significant mucinous differentiation: a characterization of intratumoral heterogeneity of KRAS mutations in mucinous and endometrioid histologic components. Int J Gynecol Cancer 28: 241-247, 2018. PMID: 29303928. DOI: $10.1097 /$ IGC .0000000000001168
37 Guerra C, Mijimolle N, Dhawahir A, Dubus P, Barradas M, Serrano M, Campuzano V and Barbacid M: Tumor induction by an endogenous K-ras oncogene is highly dependent on cellular context. Cancer Cell 4: 111-120, 2003. PMID: 12957286. DOI: 10.1016/s1535-6108(03)00191-0

38 Roylance R, Gorman P, Harris W, Liebmann R, Barnes D, Hanby A and Sheer D: Comparative genomic hybridization of breast tumors stratified by histological grade reveals new insights into the biological progression of breast cancer. Cancer Res 59: 1433-1436, 1999. PMID: 10197608.

39 Buerger H, Mommers EC, Littmann R, Simon R, Diallo R, Poremba C, Dockhorn-Dworniczak B, van Diest PJ and Boecker W: Ductal invasive G2 and G3 carcinomas of the breast are the end stages of at least two different lines of genetic evolution. J Pathol 194: 165-170, 2001. PMID: 11400144. DOI: 10.1002/path.875

40 Walker BA, Leone PE, Chiecchio L, Dickens NJ, Jenner MW, Boyd KD, Johnson DC, Gonzalez D, Dagrada GP, Protheroe RK, Konn ZJ, Stockley DM, Gregory WM, Davies FE, Ross FM and Morgan GJ: A compendium of myeloma-associated chromosomal copy number abnormalities and their prognostic value. Blood 116: e56-65, 2010. PMID: 20616218. DOI: 10.1182/blood-2010-04-279596

41 Schmidt TM, Barwick BG, Joseph N, Heffner LT, Hofmeister CC, Bernal L, Dhodapkar MV, Gupta VA, Jaye DL, Wu J, Goyal S, Chen Z, Boise LH, Lonial S, Nooka AK and Kaufman JL: Gain of chromosome 1q is associated with early progression in multiple myeloma patients treated with lenalidomide, bortezomib, and dexamethasone. Blood Cancer J 9: 94, 2019. PMID: 31767829. DOI: 10.1038/s41408-019-0254-0

42 Sawyer JR, Tricot G, Mattox S, Jagannath S and Barlogie B: Jumping translocations of chromosome 1q in multiple myeloma: evidence for a mechanism involving decondensation of pericentromeric heterochromatin. Blood 91: 1732-1741, 1998. PMID: 9473240.

43 Hing S, Lu YJ, Summersgill B, King-Underwood L, Nicholson J, Grundy P, Grundy R, Gessler M, Shipley J and PritchardJones $\mathrm{K}$ : Gain of $1 \mathrm{q}$ is associated with adverse outcome in favorable histology Wilms' tumors. Am J Pathol 158: 393-398, 2001. PMID: 11159177. DOI: 10.1016/S0002-9440(10)63982-X

Received June 22, 2020

Revised July 20, 2020

Accepted July 21, 2020 